\title{
Structure and photocatalytic influence of N-doping ATO nano-tubes on antibacterial activity toward Escherichia coli
}

\author{
Shing-Hoa Wang \\ Department of Mechanical and Mechatronic Engineering, National Taiwan Ocean University, Keelung, Taiwan, \\ shwang@email.ntou.edu.tw \\ Shiu-Mei Liu \\ Institute of Marine Biology, National Taiwan Ocean University, Keelung, Taiwan \\ Kan-Hung Hu \\ Department of Mechanical and Mechatronic Engineering, National Taiwan Ocean University, Keelung, Taiwan \\ Chien-Chon Chen \\ Department of Energy Engineering, National United University, Miaoli, Taiwan \\ Tai-Yuan Lin \\ Department of Optoelectronics and Materials Technology, National Taiwan Ocean University, Keelung, Taiwan
}

See next page for additional authors

Follow this and additional works at: https://jmstt.ntou.edu.tw/journal

Part of the Engineering Commons, and the Fresh Water Studies Commons

\section{Recommended Citation}

Wang, Shing-Hoa; Liu, Shiu-Mei; Hu, Kan-Hung; Chen, Chien-Chon; Lin, Tai-Yuan; Juang, Shuei-Wan; Yen, Chia-Yuen; Lu, Shu-Ting; and Liu, Chia-Heng (2021) "Structure and photocatalytic influence of N-doping ATO nano-tubes on antibacterial activity toward Escherichia coli," Journal of Marine Science and Technology. Vol. 29: Iss. 4, Article 14. DOI: 10.51400/2709-6998.1595

Available at: https://jmstt.ntou.edu.tw/journal/vol29/iss4/14

This Research Article is brought to you for free and open access by Journal of Marine Science and Technology. It has been accepted for inclusion in Journal of Marine Science and Technology by an authorized editor of Journal of Marine Science and Technology. 
Structure and photocatalytic influence of N-doping ATO nano-tubes on antibacterial activity toward Escherichia coli

\section{Authors}

Shing-Hoa Wang, Shiu-Mei Liu, Kan-Hung Hu, Chien-Chon Chen, Tai-Yuan Lin, Shuei-Wan Juang, Chia-Yuen Yen, Shu-Ting Lu, and Chia-Heng Liu 


\title{
Structure and Photocatalytic Influence of N-doping ATO Nano-tubes on Antibacterial Activity Toward Escherichia coli
}

\author{
Shing-Hoa Wang ${ }^{a}$,, Shiu-Mei Liu ${ }^{b}$, Kan-Hung Hu ${ }^{a}$, Chien-Chon Chen ${ }^{c}$, Tai-Yuan Lin ${ }^{\mathrm{d}}$, \\ Shuei-Wan Juang ${ }^{a}$, Chia-Yuen Yen ${ }^{b}$, Shu-Ting Lu ${ }^{b}$, Chia-Heng Liu ${ }^{a}$ \\ a Department of Mechanical and Mechatronic Engineering, National Taiwan Ocean University, Keelung 20224, Taiwan \\ ${ }^{\mathrm{b}}$ Institute of Marine Biology, National Taiwan Ocean University, Keelung 20224, Taiwan \\ ${ }^{c}$ Department of Energy Engineering, National United University, Miaoli 36003, Taiwan \\ ${ }^{\mathrm{d}}$ Department of Optoelectronics and Materials Technology, National Taiwan Ocean University, Keelung 20224, Taiwan
}

\begin{abstract}
The photocatalytic antibacterial properties of anodic titanium oxide (ATO) nanotubes in the anatase structure derived from annealing at $450{ }^{\circ} \mathrm{C}$ or $550{ }^{\circ} \mathrm{C}$ or N-doping treatment were tested on Escherichia coli under UV-A, visible light illumination, and dark conditions. Under UV-A illumination and dark conditions, in most cases, E. coli cultures containing ATO nanotubes of different treatments showed either no or slight differences in their growth from the cultures without ATO nanotubes. However, under visible light illumination, the growth of E. coli was inhibited in cultures containing ATO nanotubes. Among the three forms of ATO nanotubes, N-doped ATO nanotubes had the strongest antibacterial activity. While the antibacterial activities of both the annealed and the N-doped ATO nanotubes increased positively correlated to the increase in their total surface area.
\end{abstract}

Keywords: Visible-light, Photocatalytic antibacterial activities, Anatase $\mathrm{TiO}_{2}, \mathrm{~N}$-doping, UV-A, Escherichia coli

\section{Introduction}

A semiconductor of titanium dioxide $\left(\mathrm{TiO}_{2}\right)$ has an outstanding photocatalytic feature. Harmful organic and unwanted compounds can be destroyed by its strong oxidizing power. More importantly, $\mathrm{TiO}_{2}$ has been extensively applied to microorganisms in contaminated water and to air treatment [1,2]. The current research status of the photocatalytic effect of $\mathrm{TiO}_{2}$ on antibacterial application was reviewed in the past five years. Transparent coatings produced by stirring a $\mathrm{TiO}_{2}$-bearing suspension showed significant antibacterial activity toward Escherichia coli under low UV irradiation [3]. The photocatalytic antibacterial effects of anatase have been investigated under different irradiation methods. It has been reported that irradiation of wavelengths $>390 \mathrm{~nm}$ produced negligible photocatalytic bactericidal results on the surface of anatase. Wavelengths of UV-A/VIS light in the range of $380-390 \mathrm{~nm}$ were found to have a photocatalytic bactericidal effect similar to that of UV-A [4]. A comparison of the synergetic effects of PoPD (poly(o-phenylenediamine)), $\mathrm{TiO}_{2} @ P o P D$ (titania@poly(o-phenylenediamine)) and $\mathrm{TiO}_{2}$ was based on slow charge recombination and rapid charge separation. The photocatalytic activities of $\mathrm{TiO}_{2} @ \mathrm{PoPD}$ photocatalysts were remarkably enhanced in solar light. In addition, the antibacterial activity of $\mathrm{TiO}_{2} @ \mathrm{PoPD}$ core-shell nanocomposite has a greater effect against different pathogenic bacteria, such as Gram negative (Klebsiella pneumonia) and Gram positive (Bacillus subtills) bacteria than do PoPD and $\mathrm{TiO}_{2}$ in a diffusion process [5]. The 
antimicrobial properties of $\mathrm{Ag}-\mathrm{TiO}_{2}-\mathrm{PVDF}$ (polyvinylidene fluoride) ultrafiltration membranes can effectively prevent biofilm formation and bacteria on the surfaces of the membranes. Water treatment often involves the use of $\mathrm{Ag}-\mathrm{TiO}_{2}-\mathrm{PVDF}$ membranes [6]. Highly photoactive thin films of $\mathrm{Cu}$ doped anatase $\mathrm{TiO}_{2}$ were deposited on glass substrates by aerosol-assisted chemical vapor deposition (AACVD) [7]. The films exhibited stronglyenhanced photocatalytic activity relative to that of pure anatase and excellent antibacterial ability (vs. E. coli and Staphylococcus aureus) [7]. The exciton lifetimes were extended in $\mathrm{Cu}$ doped anatase, and the enhancement of the UV photoactivity can be explained by the interactions inside the anatase lattice between substitutional and interstitial $\mathrm{Cu}$ [7].

Reactive oxygen species (ROS), namely, hydroxyl $\cdot \mathrm{OH}$ radicals and superoxide anion ${ }^{\bullet} \mathrm{O}_{2}^{-}$radicals, can be produced by $\mathrm{TiO}_{2}$ exposed to light and have an antibacterial photocatalytic effect. These ROS have the oxidizing power to, for example, decompose various organic compounds in the outer membranes of bacteria into harmless $\mathrm{CO}_{2}$ and $\mathrm{H}_{2} \mathrm{O}$. The strong oxidizing ability of $\mathrm{TiO}_{2}$ is derived from the energy gap of the photo-induced electrons in the conduction band $(\mathrm{e}-\mathrm{cb}),{ }^{\bullet} \mathrm{O}_{2}^{-}$radicals formed by reducing $\mathrm{O}_{2}$, positive holes in the valence band $(\mathrm{h}+\mathrm{vb})$, and ${ }^{\circ} \mathrm{OH}$ radicals formed by the reaction with $\mathrm{H}_{2} \mathrm{O}$ upon ultraviolet light $(\mathrm{UV}, \lambda<380 \mathrm{~nm})$ excitation [8-10]. UV light is harmful to human beings, and this fact restricts the application of $\mathrm{TiO}_{2}$ in industry. Extensive investigations of the improvement in the photocatalytic antibacterial activity of $\mathrm{TiO}_{2}$ have been conducted with approaches such as fabricating $\mathrm{TiO}_{2}$ into nanotube layers to increase the surface area and doping it with impurities, e.g., other elements $(C, N, F, P$ and $S)$ or transition metals. In a previous work, it was shown that a $\mathrm{TiO}_{2}$ nanotube layer with an amorphous structure can be changed to the anatase form (anatase $\mathrm{TiO}_{2}$; ATO) by annealing in air at $450{ }^{\circ} \mathrm{C}$. Considerable success has also been achieved by reducing the band gap energy of ATO by doping [11]. N-doping of ATO has been reported as one of the most promising paths toward narrowing the band gap energy, and another benefit of N-doping is that it does not cause structural damage that could greatly reduce the photon conversion efficiency [12].

Testing the antibacterial responses of ATO nanotubes would provide valuable information for assessing the effects of annealing or $\mathrm{N}$-doping of the nanotubular form of $\mathrm{TiO}_{2}$ on its antibacterial activity. The motivation of this research was to investigate the photocatalytic antibacterial properties of ATO nanotubes derived by annealing at $450{ }^{\circ} \mathrm{C}$ or
$550{ }^{\circ} \mathrm{C}$, or by $\mathrm{N}$-doping, under darkness and under illumination with UV-A or visible light.

\section{Material and methods}

\subsection{The preparation of ATO nanotubes}

To prepare the $\mathrm{TiO}_{2}$ nanotubes, titanium foil (Aldrich, $99.7 \%$ purity, $0.127 \mathrm{~mm}$ thick) was immersed in electrolyte $\left(0.5 \mathrm{wt} \% \mathrm{NH}_{4} \mathrm{~F}\right.$ ammonium fluoride mixed with $\left(\mathrm{CH}_{2} \mathrm{OH}\right)_{2}$ ethylene glycol) while clamped onto a holder before being anodized at $60 \mathrm{~V}$ for $1 \mathrm{~h}$. Then the samples were annealed for $3 \mathrm{~h}$ at $450{ }^{\circ} \mathrm{C}$ in air, for $4 \mathrm{~h}$ at $550{ }^{\circ} \mathrm{C}$ in air, or for $4 \mathrm{~h}$ at $550{ }^{\circ} \mathrm{C}$ in a mixed atmosphere of $\mathrm{N}_{2} / \mathrm{Ar}$ to form channel arrays of nanotubular anatase ATO. The bandgap energy of photoluminescence (PL) for the ATO nanotubular anatase was measured with a $\mathrm{He}-\mathrm{Cd}$ laser at $10 \mathrm{~K}$ with a wavelength of $325-700 \mathrm{~nm}$. The chemical elements of the N-doped samples were determined by X-ray photoelectron spectroscopy (XPS) with a resolution of $0.1 \mathrm{eV}$ to check whether the nitrogen was doped inside the $\mathrm{TiO}_{2}$. The excitation source was Al $K_{\alpha}$ monochromatic radiation $(15 \mathrm{keV} ; 200 \mathrm{~W})$. The $\mathrm{O}$ peak at $529 \mathrm{eV}$, the Ti peak at $459 \mathrm{eV}$, the $\mathrm{N}$ peaks respectively at $396 \mathrm{eV}$ and $400 \mathrm{eV}$, and the $\mathrm{C}$ peak at $285 \mathrm{eV}$ were analyzed at a resolution of $0.1 \mathrm{eV}$.

\subsection{Antibacterial activity evaluation}

E. coli was used to test the antibacterial effects of these ATO nanotubes. After inoculation of $0.1 \mathrm{ml}$ of fresh E. coli culture into $10 \mathrm{ml}$ of Nutrient Broth medium (BD Bioscience, USA) in test tubes containing $2 \mathrm{~cm} \times 2 \mathrm{~cm}$ ATO nanotube layers, $1 \mathrm{~cm} \times 1 \mathrm{~cm}$ ATO nanotube layers, or no ATO nanotubes, the cultures were incubated at $30^{\circ} \mathrm{C}$ and $125 \mathrm{rpm}$ under UV-A light $\left(0.1 \mathrm{~mW} / \mathrm{cm}^{2}\right)$, visible light illumination, or dark conditions. The growth of E. coli in each culture was counted and determined by measuring its optical density (O.D.) at $600 \mathrm{~nm}$ spectrophotometrically every three hours. All experiments were performed in duplicate. For drawing the growth curves of these cultures, the average of the optical density at $600 \mathrm{~nm}$ were plotted against the time period.

\section{Results and discussion}

\subsection{Physical properties of the different ATOs}

The self-organized $\mathrm{TiO}_{2}$ nanotube layers of anatase in the annealed and $\mathrm{N}$-doped samples were observed by scanning electron microscopy. The tip view of the 
$\mathrm{N}$-doped ATO is shown in Fig. 1. The thickness of the nanotube layers was about $10 \mu \mathrm{m}$ (inset). Similar tip views of the $450{ }^{\circ} \mathrm{C}$ and $550{ }^{\circ} \mathrm{C}$ annealed ATO were observed respectively. The thickness of the nanotube layers was also about $10 \mu \mathrm{m}$.

The photoluminescence (PL) and XPS of the Ndoped ATO nanotube layers are shown in Fig. 2. The conversion of the band gap energies of the peaks in the PL spectrum to the wavelengths is plotted in the inset of Fig. 2(a). The N-doped ATO nanotubes $\left(\mathrm{TiO}_{2-\mathrm{x}} \mathrm{N}_{\mathrm{x}}\right)$ had a bandgap energy $(\mathrm{Eg})$ of about $2.47 \mathrm{eV}$, which corresponded to a wave length of $500 \mathrm{~nm}$. The $450{ }^{\circ} \mathrm{C}$ and $550{ }^{\circ} \mathrm{C}$ annealed ATO nanotubes had band gap energies of approximately $3.0 \mathrm{eV}$ and $2.78 \mathrm{eV}$, respectively, which corresponded to wavelengths of $413 \mathrm{~nm}$ and $450 \mathrm{~nm}$, respectively. Thus, these ATO nanotubes had a visible light photo response. The $\mathrm{N}$-doped $\mathrm{TiO}_{2}$ nanotube layer in Fig. 1 displayed the 1s core levels of the $\mathrm{N}$ spectrum shown in Fig. 2(b). Two peaks appeared at $396 \pm 0.2 \mathrm{eV}$ and $400 \pm 0.2 \mathrm{eV}$ for the nitrogen spectral signal (N 1s), respectively. The former was essentially atomic $\mathrm{N}$ or $\mathrm{NO}$ in the form of mixed titanium oxide-nitride $\left(\mathrm{TiO}_{2-x} \mathrm{~N}_{\mathrm{x}}\right)$, which corresponded to the $\beta-\mathrm{N}$ state. The latter was molecularly chemisorbed $\mathrm{N}_{2}$, corresponding to the $\gamma-\mathrm{N}$ state. This indicates that the heat treatment of $\mathrm{N}$-doping indeed successfully led to the substitution of nitrogen atoms at some oxygen sites [11,12].

\subsection{Bacteriostasis of E. coli by ATO}

The effects of the surface area of the ATO on photocatalytic antibacterial activity are shown under the dark condition in Fig. 3(a), UV-A light in Fig. 3(b), and visible light illumination in Fig. 3(c),

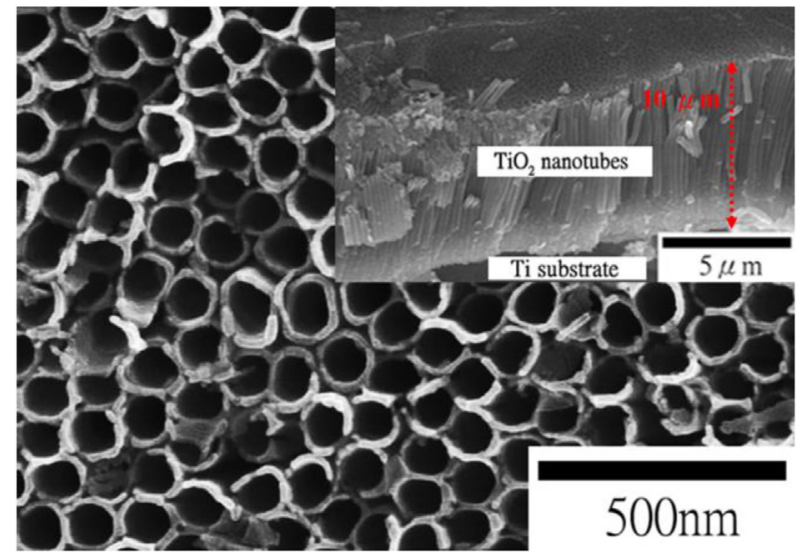

Fig. 1. SEM top views of the nanotube layers of ATO $\mathrm{N}$-doped in a gas mixture of $\mathrm{N}_{2} / \mathrm{Ar}$. The inset shows the thickness of the nanotube layers in cross-section. Similar structures were observed in ATOs annealed at $450{ }^{\circ} \mathrm{C}$ and $550^{\circ} \mathrm{C}$ respectively. respectively. The $\mathrm{N}$-doped and the $450{ }^{\circ} \mathrm{C}$ and $550{ }^{\circ} \mathrm{C}$ annealed ATO nanotubes had band gap energies corresponding to wavelengths in the visible range. Thus, these ATO nanotubes had a visible light photo response. These facts elucidated why these ATO nanotubes had antibacterial effects when illuminated under visible light but not under the UV-A light and dark conditions. As shown in Fig. 3(b), in the first $9 \mathrm{~h}$, all ATO samples showed antibacterial effects; subsequently, however, most $E$.
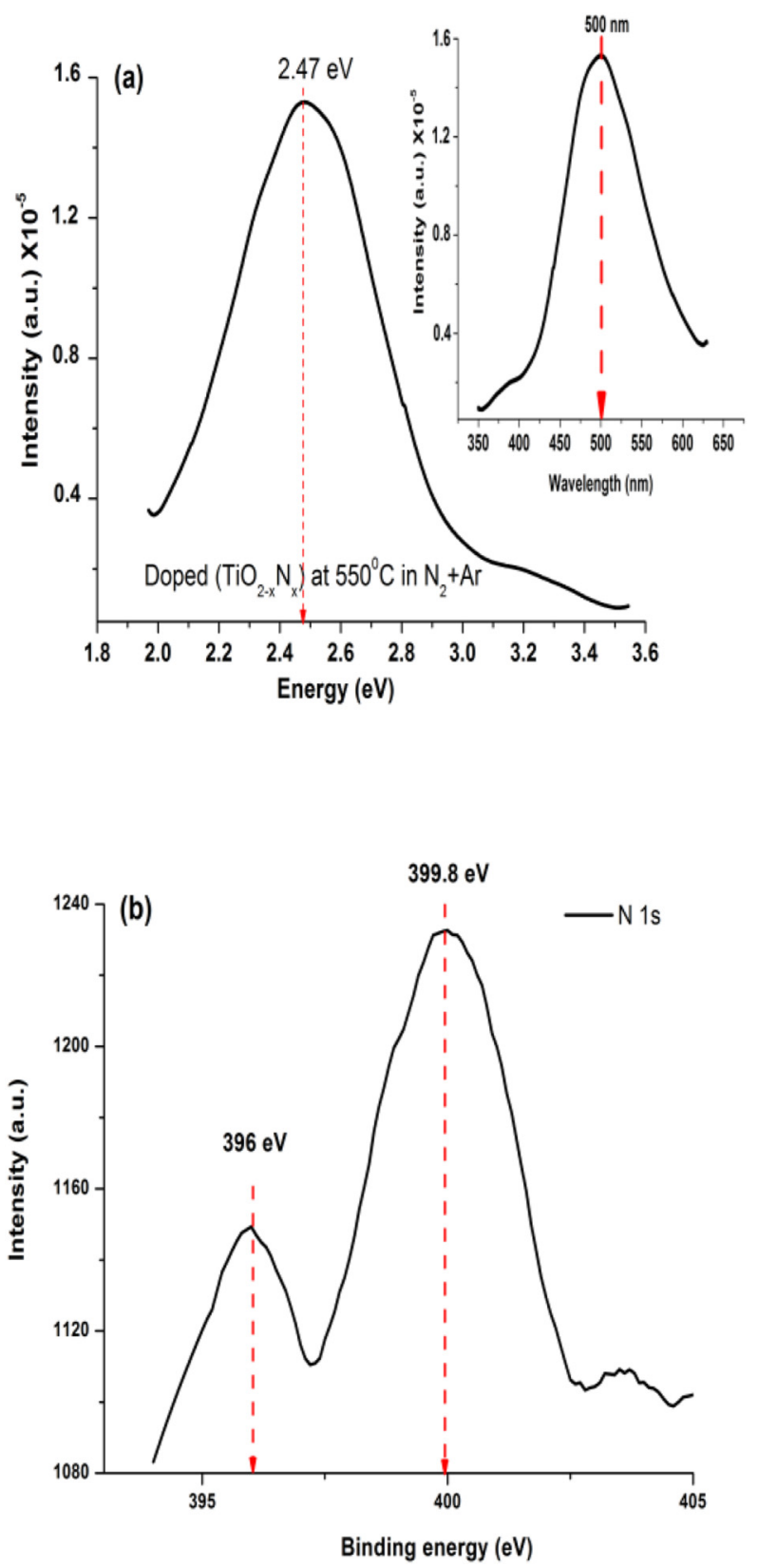

Fig. 2. (a) PL and (b) XPS spectra of the N-doped ATO nanotubular layer shown in Fig. 1. The inset in (a) is a re-plotting of the data in wavelengths $(\mathrm{nm})$. 

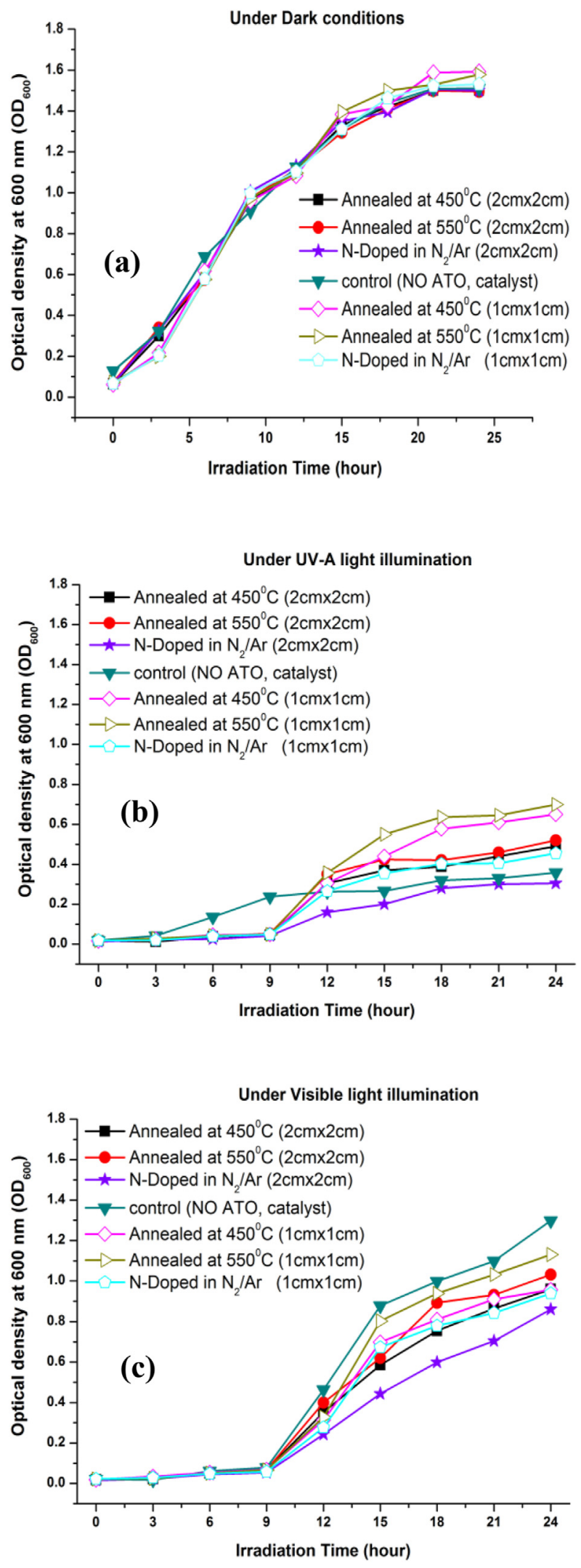

Fig. 3. The effects of surface area and ATO treatment on the photocatalysis of $\mathrm{TiO}_{2}$ were determined by measuring the growth of E. coli under (a) darkness (b) UV-A light illumination, and (c) visible light illumination. coli cultures containing ATO samples started to grow faster than did those without ATO (labeled control in Fig. 3), but not faster than the E. coli cultures containing $2 \mathrm{~cm} \times 2 \mathrm{~cm}$ layers of $\mathrm{N}$-doped ATO. The growth of the cultures containing the $2 \mathrm{~cm} \times 2 \mathrm{~cm}$ layers was inhibited more than that of the cultures containing $1 \mathrm{~cm} \times 1 \mathrm{~cm}$ layers, whether they were annealed at $450{ }^{\circ} \mathrm{C}$ or $550{ }^{\circ} \mathrm{C}$ or were $\mathrm{N}$ doped. As shown in Fig. 3(b), the $1 \mathrm{~cm} \times 1 \mathrm{~cm}$ layer of ATO annealed at $550{ }^{\circ} \mathrm{C}$ had the weakest antibacterial effect, while the $2 \mathrm{~cm} \times 2 \mathrm{~cm}$ layer of $\mathrm{N}$ doped ATO had the strongest. The reason why most cultures containing ATO samples grew better than the control group after $12 \mathrm{~h}$ under UV-A illumination in Fig. 3(b) may be that the hydrophilic and rough surfaces of the nanotubes allowed the cultures to adhere to them, which enhanced the spread and proliferation of the cultures [13], leading to growth that outpaced the antibacterial activity under UV-A light, but not in cultures containing Ndoped ATO with a larger area, the $2 \mathrm{~cm} \times 2 \mathrm{~cm}$ layers. In contrast, the surface area of a small $1 \mathrm{~cm} \times 1 \mathrm{~cm}$ layer of ATO was not large enough to generate sufficient ROS under UV-A light illumination.

On the other hand, under visible light illumination (Fig. 3(c)), all cultures containing ATO grew more slowly than did the cultures without ATO. Moreover, the growth of the cultures containing $2 \mathrm{~cm} \times 2 \mathrm{~cm}$ layers of ATO was inhibited more than that of the cultures containing $1 \mathrm{~cm} \times 1 \mathrm{~cm}$ layers, regardless of whether they were annealed at $450{ }^{\circ} \mathrm{C}$ or $550{ }^{\circ} \mathrm{C}$ or were $\mathrm{N}$-doped. ATO annealed at $550{ }^{\circ} \mathrm{C}$ had the weakest antibacterial effect, while $\mathrm{N}$-doped ATO had the strongest. The band gap energies of the ATO annealed at $450{ }^{\circ} \mathrm{C}$, ATO annealed at $550{ }^{\circ} \mathrm{C}$, and $\mathrm{N}$-doped ATO were $3.0 \mathrm{eV}, 2.78 \mathrm{eV}$ and $2.47 \mathrm{eV}$, respectively. The antibacterial activity of the ATO annealed at $550{ }^{\circ} \mathrm{C}$ was weaker than that of the ATO annealed at $450{ }^{\circ} \mathrm{C}$, possibly due to the coexistence of the anatase with a small amount of rutile. It has been reported previously that titanium oxide has better catalytic performance in the full anatase form than in the rutile form, than a mixture of the anatase and rutile forms, or than $\mathrm{TiO}_{2}$ with an amorphous structure [14].

It has been reported that doping nitrogen into the $\mathrm{TiO}_{2}$ structure to cause defects of oxygen vacancies can confer hydrophilicity to the treated specimens [15]. These vacancies can be occupied by water molecules to improve the wetting property of the surface, resulting in adsorbed hydroxyl groups [13], which contribute to the antibacterial activity under visible light illumination, especially in cultures 
containing a larger surface area of both nanotubes annealed at $450{ }^{\circ} \mathrm{C}$ and $\mathrm{N}$-doped ATO nanotubes.

\section{Conclusions}

Under dark conditions, all cultures containing ATO showed growth curves similar to those of the cultures without ATO. During the $24 \mathrm{~h}$ of incubation, the growth of $E$. coli cultures under UV-A illumination was much slower than that of cultures under visible light illumination, probably because the growth was affected by not only UV-A illumination but also the free radicals or superoxide ions produced by the ATO after UV-A illumination. Overall, ATO annealed at $450{ }^{\circ} \mathrm{C}$, ATO annealed at $550{ }^{\circ} \mathrm{C}$, and N-doped ATO had UV-A and visible light photo responses. Ndoped ATO had the strongest photo response, and the larger surface area of the ATO had a positive effect on photo response. A larger surface area allows more generation of ROS, leading to a higher photocatalytic response. In addition, the hydrophilic surfaces of N-doped ATO tend to lead to a greater number of intermediates in oxidative formation. At the same time, during the photocatalytic process under light exposure, N-doped ATO promotes the generation of ROS necessary for bactericidal action. Therefore, the antibacterial activities of N-doped ATO nanotubes become more effective as the total surface area increases.

\section{Acknowledgement}

The authors would like to thank the Center of Excellence for the Oceans of National Taiwan Ocean University, Keelung, Taiwan, for financially supporting this research. The authors also thank Professor Todd Hsu for providing instrument support and express their gratitude for the financial support from the Ministry of Science and Technology (MOST) of Taiwan under the grant MOST 109-2221-E-019-047.

\section{References}

[1] Yu CK, Hu KH, Wang SH, Hsu T, Tsai HT, Chen CC, et al. Photocatalytic effect of anodic titanium oxide nanotubes on various cell culture media. Appl Phys A 2011;102:271-4.
[2] Hu KH, Wang SH, Hsu T, Chen CC, Lin TY, Tsai HT, et al. The effect of nitrogen doped ATO nanotubes on radical multiplication of buffer media by visible-light photocatalysis rather UV. J Nanomater 2012. 2012, Article ID 510672, 6.

[3] Verdier T, Coutand M, Bertron A, Roques C. Antibacterial activity of $\mathrm{TiO}_{2}$ photocatalyst alone or in coatings on E. coli: the influence of methodological aspects. Coatings 2014;4: 670-86.

[4] Wu Y, Geis-Gerstorfer J, Scheideler L, Rupp F. Photocatalytic antibacterial effects on $\mathrm{TiO}_{2}$-anatase upon UV-A and UV-A/ VIS threshold irradiation. Biofouling 2016;32(5):583-95.

[5] Archana S, Malarvizhi M, Muthirulan P, Meenakshi Sundaram M. Superior photocatalytic and antibacterial activities of conducting ceramic $\mathrm{TiO}_{2} @$ poly(o-phenylenediamine) core-shell nanocomposites. J Mater Sci Mater Electron 2016;27:12691-700.

[6] Chen Q, Yu Z, Pan Y, Zeng G, Shi H, Yang X, et al. Enhancing the photocatalytic and antibacterial property of polyvinylidene fluoride membrane by blending $\mathrm{Ag}-\mathrm{TiO}_{2}$ nanocomposites. J Mater Sci Mater Electron 2017;28: 3865-74.

[7] Alotaibi AM, Williamson BAD, Sathasivam S, Kafizas A, Alqahtani M, Carlos SV, et al. Scanlon, and ivan P. Parkin. Enhanced photocatalytic and antibacterial ability of $\mathrm{Cu}$ doped anatase $\mathrm{TiO}_{2}$ thin films: theory and experiment. ACS Appl Mater Interfaces 2020;12:15348-61.

[8] Nakamura R, Tanaka T, Nakato Y. Mechanism for visible light responses in anodic photocurrents at $\mathrm{N}$-doped $\mathrm{TiO}_{2}$ film electrodes. J Phys Chem B 2004;108:10617-20.

[9] Macak JM, Tsuchiya H, Ghicov A, Schmuki P. Dye-sensitized anodic $\mathrm{TiO}_{2}$ nanotubes. Electrochem Commun 2005;7: 1133.

[10] Wawrzyniak B, Morawski AW. Solar-light-induced photocatalytic decomposition of two azo dyes on new $\mathrm{TiO}_{2}$ photocatalyst containing nitrogen. Appl Catal B Environ 2006;62: $150-8$.

[11] Asahi R, Morikawa T, Ohwaki T, Aoki K, Taga Y. Visiblelight photocatalysis in nitrogen-doped titanium oxides. Science 2001;293:269.

[12] Vitiello RP, Macak JM, Ghicov A, Tsuchiya H, Dick LFP. Schmuki. P. N-doping of anodic $\mathrm{TiO}_{2}$ nanotubes using heat treatment in ammonia. Electrochem Commun 2006;8: $544-8$.

[13] Bruna EN, Dini C, Cordeiro JM, Ricomini-Filho AP, de Avila ED, Rangel EC, et al. Visible-light-induced photocatalytic and antibacterial activity of $\mathrm{TiO} 2$ codoped with nitrogen and Bismuth: new perspectives to control implantbiofilm-related diseases. ACS Appl Mater Interfaces 2019;11: 18186-202.

[14] Macak JM, Ghicov A, Hahn R, Tsuchiya H, Schmuki P. Photoelectrochemical properties of N-doepd self-organized titania nanotube layers with different thicknesses. J Mater Res 2006;21:11.

[15] Garlisi C, Lai C, George L, Chiesa M, Palmisano G. Relating photoelectrochemistry and wettability of sputtered $\mathrm{Cu}-$ and $\mathrm{N}$-doped $\mathrm{TiO}_{2}$ thin films via an integrated approach. J Phys Chem C 2018;122:12369-76. 